\title{
0 rosto e a vida da sala de cinema na Lisboa do século XX
}

////////////////I Talitha Ferraz ${ }^{11}$ e João Luiz Vieira ${ }^{22}$

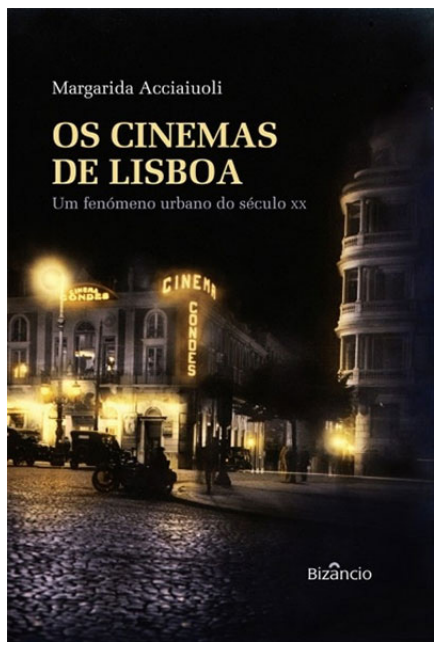

\section{Resenha}

ACCIAIUOLI, Margarida. Os cinemas de Lisboa: um fenômeno urbano do século XX. Lisboa: Bizâncio, 2012.

1. Doutoranda da Escola de Comunicação da Universidade Federal do Rio de Janeiro, com estágio doutoral na Faculdade de Ciências Sociais e Humanas da Universidade Nova de Lisboa. Professora do departamento de Comunicação Social da Universidade Estácio de Sá Rio de Janeiro. E-mail: talitha.ferraz@gmail.com

2. Professor doutor do Departamento de Cinema da Universidade Federal Fluminense. E-mail: urbanosantos5@gmail.com 
Resumo

No livro Os cinemas de Lisboa: um fenômeno do século XX, Margarida Acciaiuoli discorre sobre a relação entre os equipamentos coletivos de lazer cinematográficos e as configurações urbanas da capital portuguesa, sinalizando como a sala de exibição se engendrou nos processos de produção do espaço social e de sociabilidades da cidade, ao longo do século passado. Nossa resenha ressalta os aspectos levantados pela autora, no que concerne à trajetória do cinema como edifício-símbolo de um tempo moderno.

\section{Palavras-chave}

Sala de cinema (Lisboa), espectação cinematográfica, sociabilidades, espaço urbano, modernidade.

\section{Abstract}

In the book Os cinemas de Lisboa: um fenômeno do século XX [Movie theaters in Lisbon: a $20^{\text {th }}$ century phenomenon], Margarida Acciaiuoli makes a discuss about the relationship between collective equipment of cinema leisure and urban settings of the Portuguese capital, signaling as the exhibition was engendered in the processes of production of social space and sociabilities of the city, over the past century. Our review highlights the issues raised by the author, about the history of cinema-building as a symbol of modern time.

\section{Keywords}

Movie theaters (Lisbon), film spectatorship, sociabilities, urban space, modernity. 
As práticas de lazer ligadas às experiências do olhar associam-se, com força, desde o século XIX, a determinados espaços construídos das cidades, cujas edificações arquitetônicas mais perenes, ou mesmo arranjos físicos temporários, serviram, desde então, à acolhida de observadores e espectadores urbanos.

Os exames acerca do aparecimento de equipamentos coletivos de lazer destinados à exibição de imagem em movimento, assim como da emergência de circuitos exibidores em metrópoles e pequenas cidades, parecem, agora, ganhar um fôlego especial. $\mathrm{O}$ tema é colocado em discussão e observado justamente no contexto contemporâneo de profundas mudanças nas formas de mostrar e ver filmes. Publicações, que podemos considerar bem recentes, remontam à trajetória das intensas relações entre as salas de cinema e a configuração dos espaços urbanos de cidades como Rio de Janeiro, Niterói, São Paulo, Berlim, Bruxelas, Paris etc. (BIVER, 2009; BUSCHMANN, 2013; CAIAFA, FERRAZ, 2012; CLADEL, 2001; FERRAZ, 2009; 2012; FREIRE, 2012).

A cidade de Lisboa não ficou despercebida em meio às investigações sobre as historicidades dos cinemas citadinos enquanto estruturas físicas e locais de produção de subjetividade e de relações entre as gentes, "escuro anônimo" onde as pessoas trabalham o brilho de seus desejos (BARTHES, 1980).

O livro "Os cinemas de Lisboa: um fenômeno urbano do século XX”, editado pela Bizâncio em novembro de 2012, de autoria da professora catedrática do Departamento de História da Arte da 
Universidade Nova de Lisboa Margarida Acciaiuoli, é um trabalho vigoroso nesse sentido. A obra não apenas coloca em foco a história dos cinemas da capital portuguesa mas também articula a vida e a morte dessas salas exibidoras com o desenvolvimento e organizações espacial e sociocultural da cidade e arredores.

Em 384 páginas, divididas em seis capítulos, a autora mostra como o cinema - e seus prédios facilmente reconhecíveis, destacados na paisagem construída através de suas fachadas (rostos) - agiu na configuração da urbe lisboeta, marcando os traçados físicos das ruas, os trajetos e afetos das pessoas, os laços de sociabilidade, os imaginários e as identidades da região. Margarida Acciaiuoli recorre a dados de arquivos, reportagens de época e fotografias coletados por ela a partir de 1982, quando uma primeira versão da investigação foi pensada para um trabalho de mestrado. $\mathrm{O}$ recorte temporal do estudo é de um século.

A autora segue das seminais experiências de espectatorialidade de imagens animadas e filmes, passando pelo auge das "grandes catedrais" - como Acciaiuoli chama os movie palaces lisboetas até chegar à atual era do multiplex (ou multissalas). Nessa fase, a escritora constata ter havido uma mudança no estatuto do espectador, que, segundo afirma, se tornou mero público, despontando daí uma completa alteração do que é a "ida ao cinema”.

Notando que o ato de "ir ao cinema" não se circunscreve apenas a "ir ver um filme", a pesquisadora busca em alguns momentos da obra apresentar a mais-valia dos equipamentos de exibição, os quais, conjugados com o filme, produzem efeitos que ressoarão nas pessoas durante gerações inteiras. Margarida Acciaiuoli defende que a sala de cinema é muito mais do que um espaço neutro. Mostra, ao longo do livro, ao contar os meandros dos processos de construção das salas exibidoras lisboetas, que rapidamente os arquitetos perceberam que a estrutura do cinema poderia se tornar um prolongamento do filme. O movimento do cinema não se esgota na projeção e na tela animada; ele transborda e se coaduna com os ambientes arquiteturais e seus elementos físicos.

Com foco no final do século XIX e no início do século XX, épocas marcadas pelo aparecimento de uma vida citadina mais 
pujante na Europa, a primeira parte do livro debruça-se sobre os pormenores do surgimento das experiências de espectatorialidade em Lisboa. O leitor é situado de forma que perceba a relação estreita da cidade com as experimentações de um pré-cinema e com a subsequente consolidação do cinema de moldes comerciais. A autora expõe como, pouco a pouco, os equipamentos coletivos de lazer cinematográficos se sedentarizaram em Lisboa.

$\mathrm{Na}$ figura de edifícios adequados àquela nova arte do final de século XIX, o cinema passou a ter um rosto específico: suas fachadas. Margarida demonstra que foi por meio desses rostos diversos - ora lapidados ao estilo art déco, ora arrumados segundo estéticas art nouveau - que o prédio do cinema, para ela, o edifício-símbolo do século XX, começou a ser reconhecido por quem percorria trajetos nas ruas.

Os circos também são destacados pela autora como importantes locais de tessituras dos lazeres modernos e sociabilidades lisboetas à época. Não é arriscado dizer, após a leitura, que os cinemas de Lisboa nasceram no circo, a exemplo do Real Coliseu, de 1887, e o Coliseu dos Recreios, de 1890. Para além das companhias de palhaços, os circos traziam para o público os chamados "fenômenos" e as novidades técnicas - entre elas, as imagens em movimento. O Real Coliseu e o Coliseu dos Recreios foram espaços versáteis e estabilizaram-se como teatros-circos, uma invenção genuinamente portuguesa, segundo a pesquisadora.

As páginas seguintes se lançam a partir de uma metodologia meticulosa alicerçada pelo manejo de dados coletados em periódicos, catálogos de exposições e anuários comerciais, cruzados com uma vasta bibliografia especializada nas áreas de urbanismo, cinema, artes e história. Logo a atenção se volta para os cinemas da primeira metade do século XX e o seu funcionamento fortemente integrado à vida moderna em sociedade. A professora mostra que os seminais equipamentos exibidores lisboetas foram também peças fundamentais de uma urbanização protuberante.

Ao mesmo passo que viu nascer o lazer cinematográfico, expressão de uma novidade pujante, de presença ativa nas ruas, a cidade inaugurou as suas grandes artérias de circulação, a 
exemplo da marcante, e então recentíssima, avenida da Liberdade. Nas quatro primeiras décadas do século passado, em Lisboa, foi evidente a escalada de uma diversidade urbana apanhada de cafés, vida noturna, espaços de convivência e, logicamente, cinemas. Entre eles, Tivoli, Capitólio e Parque Mayer, além de várias salas de bairro, remetiam-se a noções que a autora chama de "templo" e "fábrica". Templos do espetáculo, fábricas de sonhos e ilusões.

Contando em pormenores o funcionamento do mercado exibidor lisboeta das primeiras décadas do século passado, a autora fala a respeito das fachadas publicitárias e dos cartazes pintados à mão, que faziam menção a cenas de filmes literalmente "em cartaz". Margarida coloca em evidência as relações intrínsecas que existiam nesse tempo entre arquitetura, desenhistas e publicidade. O ÉdenTeatro é o caso de destaque. Por anos, antes das padronizações impostas por empresas distribuidoras, conta Acciaiuoli, um pintor contratado assistia aos filmes principais da programação do Éden, sempre antes da estreia oficial e geralmente ao lado do dono da sala. Em seguida, ambos, capitalista e artista, decidiam como o cartaz poderia evocar as cenas e os personagens da película.

Formação de plateia, mudança nos estatutos das salas perante os diferentes pedaços da cidade e até mesmo a intervenção das revistas de cinema na complementação do gosto do público e na construção de sua experiência de espectador são contextualizadas pela autora como marcas indeléveis da primeira metade do século XX.

Discorrendo acerca dos fenômenos socioculturais da década de 1950, o livro detém-se na análise do aparecimento do modelo movie palace em Lisboa. Um dos exponentes foi o Cinema São Jorge, que até hoje se mantém em funcionamento com diversas mostras e festivais cinematográficos, sessões de peças de teatro e eventos musicais.

Surgia, assim, nos anos 40 e 50, a era das "catedrais": época na qual a cidade foi dotada de cinemas grandiosos, isto é, verdadeiros marcos referenciais que ingressaram na produção de uma Lisboa cosmopolita. Se nos anos 20 e 30 o cinema era pensando segundo os modelos do "templo" e da "fábrica”, com o fim da Segunda Guerra Mundial, a partir de 1945, para a escritora, essas analogias 
já não fariam mais sentido. Ao contrário, nessa fase seriam as “catedrais" que pontuariam Lisboa nos eixos de desenvolvimento urbano. Avenida da Liberdade, com o São Jorge. Praça do Saldanha, com o Monumental, entre tantos outros cinemas citados por Margarida Acciaiuoli.

Já no dorso mais contemporâneo dentro do recorte histórico do livro, o exame se volta para o cenário de mudanças efetivadas pelo avanço da TV, por alterações na legislação sobre a frequência etária dos cinemas, por novas políticas de preço etc., pontos que provocam a construção de outros costumes e práticas nas décadas ulteriores. Tais transformações são observadas pela obra como fatores que logo resultariam na reorientação física das salas e no retalhamento das "catedrais". O cinema, nos anos 60 e 70, desce às caves dos prédios para poder utilizar outros espaços, e deixa, paulatinamente, de ter rosto. É então aí que o estudo mostra como essa torção abriu caminho para que os equipamentos coletivos de lazer cinematográfico fossem tragados pelos centros comerciais isto é, na fala brasileira: os shopping centers - , que não tardaram em aparecer em Lisboa.

Sempre relacionando os modelos de salas aos desenvolvimentos citadinos de Lisboa, Acciaiuoli demonstra como cinema e cidade se articularam de maneira profícua, o que gerou formas diversas de usos e configuração do urbano ao longo do tempo e motivou nuances criadoras para as práticas de lazer e sociabilidade na capital de Portugal.

A autora ainda ressalta, na parte quase final do livro, os cinemasestúdios ou salas-estúdios. Estende-se no exemplo do Londres, um cinema inaugurado em 1972, que também tinha as funções de snack bar e pub, na avenida de Roma. Esse perfil de sala reunia cinemas menores, que representaram os últimos lances de fôlego de um setor de exibição já em crise. Eram apostas na tentativa de soerguer os cinemas de rua da cidade.

Com a entrada peremptória do cinema de shopping na vida cotidiana das pessoas e a consequente derrocada dos cinemas que antes ocupavam trechos de grandes avenidas ou ruas dos bairros lisboetas, foi a perda das fachadas desses equipamentos o fato cruel 
mais evidente, de acordo com as análises da pesquisadora. Para ela, perderam-se, com isso, referências espaciais proeminentes, que antes conferiam razões aos trajetos e à imagem urbana das cidades.

É nesse aspecto que Lisboa se traduz como qualquer capital ou cidade do interior ocidental, onde os cinemas se esvaíram dentro da profusão urbana, tal como rostos podem ser recortados ou apagados em um álbum de família, nosso ou de desconhecidos. 


\section{Referências}

ACCIAIUOLI, M. Os cinemas de Lisboa: um fenômeno urbano do século XX. Lisboa: Bizâncio, 2012.

BARTHES, R. Saindo do Cinema. In: BELLOUR, R. (Orgs). Psicanálise e cinema. São Paulo: Global, 1980.

BIVER, I. Cinéma de Bruxelles: portraits et destins. Bruxelas: CFC Editions, 2009.

CAIAFA, J.; FERRAZ, T. "Comunicação e sociabilidade nos cinemas de estação, cineclubes e multiplex do subúrbio carioca da Leopoldina”. Galáxia, São Paulo, v. 12, n. 24, dez. 2012.

CLADEL, G. et al (Dir.). Le Cinéma dans la cité. Paris: Éditions du Félin, 2001.

FERRAZ, T A segunda Cinelândia carioca: cinemas, sociabilidade e memória na Tijuca. Rio de Janeiro: Multifoco, 2009.

A segunda Cinelândia carioca. Rio de Janeiro: Mórula Editorial, 2012.

FREIRE, R. de L. Cinematographo em Nichteroy: história das salas de cinema de Niterói. Niterói: Niterói Livros; Rio de Janeiro: Inepac, 2012.

GONZAGA, A. Palácios e poeiras: 100 anos de cinemas no Rio de Janeiro. Rio de Janeiro: Record; Rio de Janeiro: Funarte,1996.

SANTORO, P. F. A relação da sala de cinema com o espaço urbano em São Paulo: do provinciano ao cosmopolita. Dissertação (Mestrado) - Universidade de São Paulo, Faculdade de Arquitetura e Urbanismo, São Paulo, 2004. 